\title{
BIOPOLÍTICA: OS PARADOXOS DE CONTROLAR E MATAR
}

\author{
BIOPOLITICS: THE PARADOXES OF \\ CONTROLLING AND KILLING
}

\section{Elias de Nazaré Moraes ${ }^{1}$ Ernani Pinheiro Chaves ${ }^{2}$}

\begin{abstract}
Resumo: O presente artigo tem como objetivo apresentar a compreensão da análise de Michel Foucault sobre a biopolítica como uma gestão da vida e os paradoxos decorrentes dessa gestão, que perpassa a questão da sexualidade que conecta o controle disciplinar à biopolítica, assim como à normalização e aos modos de subjetivação que constituem o sujeito moderno. Aborda, também, a questão do estado de exceção e do racismo, considerados como aspectos negativos relacionados ao cuidado com a vida, quando decide matar. Destaca ainda os comentários de Giorgio Agamben sobre a vida nua no âmbito da zoé e do bíos a partir da perspectiva de politização da vida e de Roberto Esposito sobre a imunização da vida, a partir do qual é possível encontrar uma visão positiva da biopolítica.
\end{abstract}

Palavras-chave: Biopolítica. Sexualidade. Norma. Vida. Racismo.

\begin{abstract}
This article aims to present Foucault's understanding of biopolitics as a life management and the paradoxes arising from this management that crosses the question of sexuality that links disciplinary control to biopolitics, as well as the normalization and modes of subjectivation that constitutes the modern subject. It also addresses the issue of state of exception and racism, negative aspects of this care for life when it decides to kill. Also worthy of note is Agamben's comments on bare life in zoé and bios in a politicization of life and Esposito on the immunization of life where in this it is possible to find a positive view of biopolitics.
\end{abstract}

Keywords: Biopolitics. Sexuality. Norm. Life. Racismo.

\section{BIOPOLÍTICA E SEXUALIDADE}

A compreensão analítica de Foucault sobre biopolítica tem como referência o modo segundo o qual o poder se encaminhou na Modernidade, entre o fim do século XVIII e início do século XIX, com o surgimento das ciências humanas utilizadas como estratégia no domínio do biopoder e nas transformações que ocorreram nesse período, a fim de governar, de classificar e de ordenar os indivíduos, bem como todo o conjunto da população, através de uma série de procedimentos disciplinares e de biopoderes locais, com a intenção de organizar a gestão da vida politicamente e torná-la uma força produtiva (cf. REVEL, 2011, p. 24). Neste sentido, Michel Foucault afirma que a biopolítica é

\footnotetext{
${ }^{1}$ Mestrando do Programa de Pós-graduação em Filosofia da Universidade Federal do Pará.

Orcid: http:/ / orcid.org/0000-0002-6571-0201

2 Professor da Universidade Federal do Pará - Programas de Pós-graduação em Filosofia e Psicologia.

Orcid: http://orcid.org/0000-0002-8988-1910
} 
[...] a maneira como se procurou, desde o século XVIII, racionalizar os problemas postos à prática governamental pelos fenômenos próprios de um conjunto de viventes constituídos em população: saúde, higiene, natalidade, longevidade, raças... Sabe-se o lugar crescente que esses problemas ocuparam desde o século XIX e que desafios políticos e econômicos eles vêm constituindo até hoje (FOUCAULT, 2008a, p. 431).

No campo da biopolítica, Foucault analisa os delineamentos genealógicos que levou ao surgimento de um importante dispositivo para tornar a vida mais produtiva e docilizada, o poder disciplinar. Este "[...] poder que se aplica singularmente aos corpos pelas técnicas da vigilância, pelas punições normalizadoras, pela organização panóptica das instituições punitivas" (FOUCAULT, 2005, p. 329). Deste modo, a disciplina alcançou todos os espaços possíveis, atingindo tanto a população, quanto o indivíduo.

A disciplina como um dos modos de agir do poder implica, segundo Revel (2011, p. 24), numa compreensão histórica da conjuntura da racionalidade política do Estado e do nascimento do Liberalismo e, ao mesmo tempo, o desenvolvimento do Capitalismo, na qual surge a biopolítica como uma tecnologia do poder que descobre a população e a transforma em seu objeto, aplicando sua estratégia de controle e normalização.

Com a descoberta da população desenvolveram-se outros dispositivos que contribuem com a gestão e o controle sobre as vidas, dirigindo-se diretamente ao corpo, como é o caso da sexualidade, que liga o poder disciplinar à biopolítica (cf. FOUCAULT, 1999a, p. 118119). Foucault (2008a, p. 27) se refere aos objetos da biopolítica como tecnologias de materialização do poder que pretendem mostrar como uma série de práticas num regime de verdades constituem os dispositivos de poder-saber, que submetem e demarcam o que pode ser considerado verdadeiro ou falso epistemológica e socialmente.

Para Foucault (1999a, p. 93), a biopolítica está ligada às questões éticas e, neste sentido, a sexualidade aparece como ponto de conexão com o poder em três dimensões: a teórica, a prática e a política. Na dimensão teórica destaca-se a questão da verdade que, segundo o filósofo, tornou a sexualidade possível através de técnicas de saber e de procedimentos discursivos como um importante campo a ser explorado. Os discursos de verdades que, para Foucault (2005, p. 336-337), surgiram com a sexualidade exerceram uma importante função normalizadora e controladora dos comportamentos dos indivíduos e da população, bem como dirigem-se ao treinamento dos corpos. Neste sentido, Candiotto (2007, p. 211) observa que, no pensamento de Foucault, a verdade e a sexualidade não existem como objetos naturais-físicos, mas como discursos verdadeiros que se inscrevem no plano teórico do biopoder. Deste modo, o prazer ligado à verdade se difere do prazer físico-sexual e "[...] explica a captura política do corpo por meio de um discurso de verdade; o corpo é também o lugar em que a vida desdobra sua potência, individual e coletivamente" (ADVERSE, 2016, p. 940).

A sexualidade têm uma dimensão teórica e outra prática e, esta última dimensão a insere no campo da ética. Segundo Abraham (1992, p. 60), Foucault colocou o tema da sexualidade não no domínio da lei ou da família, mas a partir dos corpos e dos seus prazeres, assim como no biopoder. Assim, a sexualidade se apresenta como um dispositivo da biopolítica realizada pelo Estado moderno, que estabelece as práticas de controle sanitário, de natalidade, de mortalidade e de a atenção ao demográfico, de modo que os temas relacionados à vida e à morte da população vão distinguir e caracterizar eficazmente a Modernidade. Observa-se, assim que: 
O desenvolvimento de campos de conhecimentos diversos (que cobriram tanto os mecanismos biológicos da reprodução como as variantes individuais ou sociais do comportamento); a instauração de um conjunto de regras e de normas, em parte tradicionais e em parte novas, e que se apóiam [sic] em instituições religiosas, judiciárias, pedagógicas e médicas; como também as mudanças no modo pelo qual os indivíduos são levados a dar sentidos e valor a sua conduta, seus deveres, prazeres, sentimentos, sensações e sonhos. [...] constitui-se uma "experiência" tal, que os indivíduos são levados a reconhecer-se como sujeitos de uma "sexualidade" [...] (FOUCAULT, 1998, p. 9-10).

Na dimensão política, Corrêa (2009, p. 498) comenta que, ao falar sobre sexualidade, Foucault analisou no nível do indivíduo e sua liberdade no horizonte do poder político referente ao descontrole dos desejos de forma tirânica, de modo que o tirano é aquele que não consegue governar a si mesmo e, por isso, oprime os outros. A tirania dos apetites sexuais apareceu como atitude repressora e, portanto, será preciso saber dominá-los, o que tornou possível o aparecimento de técnicas do cuidado de si, tais como a ascese e a obediência.

Na conferência Sexualidade e Poder, Foucault (2004, p. 64-65) mostra que o Cristianismo não destruiu a cultura grega como se poderia pensar, mas, ao contrário, absorveu muitas ideias morais e éticas que faziam parte da vida de determinados grupos da época. $\mathrm{Na}$ Grécia antiga e no Império Romano nem tudo era permitido, pois já existia certo rigor moral em algumas práticas, como no caso do casamento monogâmico e o autocontrole do desejo sexual, os prazeres.

O Cristianismo inova nas técnicas, como mecanismo de poder para impor essa moral, sendo um exemplo disso é a obediência. Na política, o dispositivo de obediência às leis, aos dogmas e à hierarquia desenvolveu suas técnicas no exercício do poder pastoral, que apresenta como característica, por um lado, o cuidado com a população enquanto rebanho e, por outro lado, a individualização da ovelha deste rebanho (cf. FOUCAULT, 2004, p. 64-66).

\section{A NORMALIZAÇÃO BIOPOLÍTICA}

Na passagem do século XVIII ao XIX surgiu algo novo, descobriu-se um importante objeto a ser explorado: o corpo, que é considerado uma fonte de riquezas. Por isso, é preciso disciplinar, adestrar, docilizar o corpo para o trabalho e, assim, produzir riquezas (cf. FOUCAULT, 1999b, p. 163-165). O corpo se torna fundamental como produtor e reprodutor, porém ele precisa ser preparado através do poder disciplinar, que também está ligado ao dispositivo de sexualidade. Deste modo, para Foucault (1999a, p. 131-133), o biopoder, como tecnologia do poder, usou a analogia do corpo anatômico e aplicou-o ao corpo social numa compreensão anátomo-política, e que se tornou indispensável ao desenvolvimento do capitalismo para preparar os corpos e para potenciá-los produtiva e economicamente. Neste sentido, “[...] a proliferação das tecnologias políticas que, a partir de então, vão investir sobre o corpo, a saúde, as maneiras de se alimentar e de morar, as condições de vida, todo o espaço da existência" (FOUCAULT, 1999a, p. 135). Em sua obra Os anormais, Foucault afirma sobre a relação do corpo com a disciplina, a economia e o biopoder,que:

[...] vemos crescer no exército, nos colégios, nas oficinas, nas escolas, todo um disciplinamento do corpo, que é o disciplinamento do corpo útil. Aperfeiçoam-se novos procedimentos de vigilância, de controle, de distribuição no espaço, de anotação, etc. Temos todo um investimento 
do corpo por mecânicas de poder que procuram torná-lo ao mesmo tempo dócil e útil. Temos uma nova anatomia política do corpo (FOUCAULT, 2001, p. 244).

$\mathrm{Na}$ análise de Foucault (2005, p. 42-43), o poder disciplinar se desdobra, também, sobre o tempo da fábrica que está ligado ao tempo da vida que, juntamente com a norma, organizou o trabalho nos séculos XVIII e XIX dando, assim, uma importante contribuição para a economia capitalista e na formação da sociedade que lhe é correlativa. Esse poder produz saberes, verdades e disciplinamento dos sujeitos ao selecioná-los, normalizá-los, hierarquizá-los e ao centralizar seus efeitos no corpo do indivíduo, pois o que estava no interior do indivíduo, do corpo sujeitado, é extraído, o que provoca um desbloqueio epistemológico, fazendo surgir na ciência uma nova relação entre poder e saber (FOUCAULT, 2005, p. 220-222). Este poder disciplinar escapa ao poder soberano e se faz presente em todos os meios e de diferentes modos, inclusive na gestão da vida pelo biopoder.

Para Foucault (2005, p. 286-288), no curso Em defesa da sociedade, há certa estatização do biológico, assim como existe uma ruptura do poder soberano para a biopolítica, que diferencia entre sexualidade individual e o corpo social. Tal ruptura se expressa no direito exercido pelo soberano sobre a vida do súdito na política do fazer morrer e deixar viver, que transita para uma política do cuidado com a vida e para fazê-la proliferar. A vida do súdito está vinculada à vontade do soberano e o efeito dessa vontade "[...] só se exerce a partir do momento em que o soberano pode matar. [...] o direito de matar é que detém efetivamente em si a própria essência desse direito de vida e de morte" (FOUCAULT, 2005, p. 286-287).

Sobre a sexualidade, Foucault (2005, p. 300-301) analisa a diferença entre sexualidade individual e o corpo social, ao destacar a importância estratégica e a valorização médica que se deu durante o século XIX em relação à sexualidade, bem como à preocupação com a degenerescência, que se insere numa articulação disciplinar e regulamentadora do corpo físico do indivíduo, estendendo-se a todo corpo social da população. Deste modo,

[...] a sexualidade, enquanto comportamento exatamente corporal, depende de um controle disciplinar, individualizante, em forma de vigilância permanente [...], e depois, por outro lado, a sexualidade se insere e adquire efeito, por seus efeitos procriadores, em processos biológicos amplos que concernem não mais ao corpo do indivíduo mas a esse elemento, a essa unidade múltipla constituída pela população (FOUCAULT, 2005, p. 300).

No século XVIII surgiu uma nova tecnologia de poder que integrou a disciplina e a modificou, bem como a direção e os efeitos, formando, assim, dois polos do poder sobre a vida. Essa tecnologia é chamada de biopolítica e se dirige ao homem enquanto espécie humana, o que permitiu fazer uma diferenciação entre o homem-espécie em relação ao homem-corpo (indivíduo). Partindo da análise anátomo-política do corpo humano (corpo social) para uma biopolítica da espécie humana (população). Tal tecnologia se direciona à multiplicidade dos homens, aos processos do conjunto da vida, à massificação dos indivíduos e não mais ao corpo individual, nem mesmo aos processos de individualização (cf. FOUCAULT, 2005, p. 288-289).

$\mathrm{Na}$ diferença analítica entre indivíduo e espécie, Foucault (1999a, p. 131-135) aborda na obra $A$ vontade de saber uma questão importante no campo da biopolítica, que é a distinção entre bios e zoé. Nesta está o corpo anatômico, individualizante e matável; e naquela o biológico, especificante e feito para permitir viver. Deste modo, a zoé está ligada à compreensão

PRACS: Revista Eletrônica de Humanidades do Curso de Ciências Sociais da UNIFAP https://periodicos.unifap.br/index.php/pracs ISSN 1984-4352 Macapá, v. 12, n. 1, p. 65-75, jan./jun. 2019 
do corpo físico, enquanto que, na Modernidade biológica, a espécie entra na estratégia política. Isso quer dizer que: "O homem, durante milênios, permaneceu o que era para Aristóteles: um animal vivo e, além disso, capaz de existência política; o homem moderno é um animal, em cuja política, sua vida de ser vivo está em questão" (FOUCAULT, 1999a, p. 134).

Na obra Homo Sacer, Agamben (2007, p. 9-12) entende que, para Aristóteles e para os gregos, a discussão sobre a política começa a partir da distinção entre zoé e bíos. A zoé se refere à vida nua, reduzida ao aspecto físico-natural, mas que, ao se revestir de cultura, a vida nua passa a ser qualificada. A vida natural passa a estar ligada à casa e à reprodução, permanecendo fora da vida pública da pólis, embora não desligada da ética. Segundo Agamben (2007, p. 9-12), Foucault analisa esta distinção para mostrar que, na Modernidade, especialmente a partir do século XVIII e com o surgimento da biopolítica, a vida natural ${ }^{3}$ não vai ser abandonada, pois a zoé é importante e foi introduzida na política. O corpo e a vida na casa (oikos) se tornou importante para o Estado e para a política.

O racismo de Estado, para Foucault (1999a p. 140-141), foi uma das maneiras de introduzir a vida em nível do corpo na biopolítica. Com a biologização e a estatização do racismo, a Psiquiatria exerceu, de um lado, o papel indispensável de justificação da teoria da degenerescência da raça e a norma, de outro lado, organizou os espaços e a população para proteger o sangue e a raça. O nazismo foi o extremo dessa biopolítica junto com o antigo direito do poder soberano de matar. Neste aspecto, Castro (2009, p. 377) diz que o racismo se tornou “[...] uma estratégia global do Estado, uma estratégia que a sociedade exerce sobre si mesma em termos de purificação permanente e normalização social”. Foucault (1999a, p. 140-141) observa que a Psicanálise não entra no biopoder, ela resiste a partir da ruptura com a neuropsiquiatria e se opõe criticamente em relação à teoria da hereditariedade e da degenerescência.

No campo da biopolítica vale ressaltar ainda a compreensão de Foucault (2005, p. 172) sobre as concepções de povo, de massa e de população. A noção de povo está ligada, incialmente, ao território, ao chão a que pertence ao rei. Na Modernidade, no entanto, esse povo foi considerado o povo soberano, conceito este herdado da soberania oriundo dos reis (cf. FOUCAULT, 2005, p. 278). Genealogicamente, Foucault (2008a, p. 152) se refere ao povo em outro momento, como fundamento do direito e objetivo final do Estado. Deste modo, o Estado se torna um instrumento da vontade do povo, pois este se constitui como sujeito de direito e não aquele (FOUCAULT, 2008a, p. 235).

Diferentemente do povo, a massa se refere à multidão e à cidade. No século XIX, com as fábricas surgiu a ideia de massa vinculada à cidade operária. A noção de Estado, para Foucault (2005, p. 297-299), também apresenta certa ligação com a massa e a massificação da população. Neste sentido, o processo do êxodo rural para a cidade, impulsionado pela industrialização, contribuiu para a formação das massas, processo este em que o indivíduo desaparece e perde a sua identidade.

A população, por sua vez, faz referência a algo numerado, codificado, controlado, normalizado, estabelecido estatisticamente (cf. FOUCAULT, 2015, p.148). Assim, para Foucault (2015, p. 422-424), a população tem seus fenômenos, suas regularidades, suas características e seus efeitos próprios que foram revelados pela estatística, que se mostra diferente do antigo

\footnotetext{
${ }^{3}$ Para Dreyfus e Robinow (1995, p. 120-121), Foucault nega a natureza dos objetos o que tornou possível todas as suas análises, o que leva a entender que, para Foucault, não existe natureza humana, mas a vida qualificada. Segundo Wellausen (2007, p. 13) pode-se se falar em natureza como processo de subjetivação do sujeito.
} 
modelo familiar de governar. Compreende-se, desta maneira, a população como o objeto da biopolítica e do biopoder. Diante disso, o povo resiste à regulação da população e subsiste em destaque, de modo que:

O povo é aquele que se comporta em relação a essa gestão da população, no próprio nível da população, como se não fizesse parte desse sujeito-objeto coletivo que é a população, como se se pusesse fora dela, e, por conseguinte, é ele que, como povo que se recusa a ser população, vai desajustar o sistema (FOUCAULT, 2008b, p. 57).

O poder precisa de duas importantes aliadas para se exercer sobre a população: a norma e a lei. Esta se estabelece no plano jurídico do direito (FOUCAULT, 2005, p. 19-20; 338), e se refere às condutas e aos atos individuais que qualificam o permitido e o proibido, bem como torna legal a condenação (CASTRO, 2009, p. 310). A norma é o que pode ser aplicado a um corpo, tendo como referência a ideia de normal, de normalidade (estatística). Não está ligada à transgressão, mas à regulação que está na média e que naturaliza as coisas. A ação da norma é permanente e preventiva da má ação, que está no campo da subjetividade (cf. FOUCAULT, 1999a, p. 135-136). Para Castro (2009, p. 310), a norma é um princípio regulador das condutas e um diferenciador, que hierarquiza e que quantifica, que homogeneíza e que medicaliza a população. Norma e disciplina estão ligadas entre si através do corpo biológico como ponto de aplicabilidade e efeito.

No campo das tecnologias que produzem efeitos de poder encontram-se as práticas de subjetivação que, para Foucault (1993, p. 205), constituem o sujeito. Não se nasce sujeito, mas torna-se sujeito. Por sua vez, em referência ao sujeito de Foucault, Candiotto (2006, p. 67) diz que pelos modos de subjetivação "[...] busca-se saber como alguém, numa prática histórica específica, torna-se [grifo do autor] sujeito, qual seu estatuto, sua posição, sua função e os limites do seu discurso". Para Revel (2011, p. 147), o sujeito pode se constituir tanto por práticas de poder ou de conhecimento, segundo uma teia de poder-saber, bem como por meio de técnicas de si.

Ao investigar os modos de subjetivação e de constituição do sujeito, Wellausen (2007, p. 13) menciona que, em Foucault, não existe uma natureza humana, mas antes a explicitação de uma microfísica do poder e das relações entre forças. Nesse sentido, o delinquente é um exemplo disso, pois ele não nasceu delinquente, mas tornou-se. Pode-se falar em natureza como processo de subjetivação do sujeito ou de querer naturalizar pela norma. Segundo Ternes (2011, p.142), esse sujeito é o resultado da luta entre o nascimento e a morte do processo histórico da Modernidade, que subjetivou o eu. Portanto,

[...] através da história, a constituição de um sujeito que não é dado definitivamente, que não é aquilo a partir do que a verdade se dá na história, mas de um sujeito que se constitui no interior mesmo da história, e que é a cada instante fundado e refundado pela história (FOUCAULT, 2002, p. 10).

Da mesma maneira, analiticamente para o filósofo (2005, p. 299-300), a procriação não é natural, se fosse natural os governos não incentivariam ou regulariam segundo seus interesses, como fazem com a força de produção dos trabalhadores. Seguindo esse pensamento, Agamben comenta que, 
[...] os "processos de subjetivação" que, na passagem entre o mundo antigo e a moderno, levam o indivíduo a objetivar o próprio eu e a constituir-se como sujeito, vinculando-se, ao mesmo tempo, a um poder de controle externo, e não transferiu suas próprias escavações, como teria sido até mesmo legítimo esperar, ao que poderia apresentar-se como o local por excelência da biopolítica moderna (AGAMBEN, 2007, p. 125).

São os processos de subjetivação e individualização que afirmam quem eu sou e meu objeto como se refere Paul Veyne, "O sujeito não é constituinte, é constituído como o é o seu objeto [...]” (VEYNE, 2009, p. 102). Os processos históricos sejam da subjetivação ou da regulamentação da força de trabalho, ambos se inscrevem como polos de destaque na Modernidade e estão vinculados com a tecnologia da biopolítica no governo da vida, bem como as ciências humanas, na sua pretensão de dizer quem é esse sujeito e quem é o indivíduo. Tais tecnologias produzem efeitos tanto no nível do bíos quanto da zoé.

\section{ZOÉ E BÍOS: A VIDA POLITIZADA}

Com a mudança do território (poder soberano) para a população/sociedade (biopoder), há uma animalização do homem e, ao mesmo tempo, a politização da zoé. Tal politização permite uma ciência sobre o homem e possibilita o surgimento da Psiquiatria, da Psicologia, Antropologia e demais ciências humanas. Antes do século XVIII não era possível o aparecimento de tais ciências. Daí a importância deste contexto político e científico, que se torna fundamental para o progresso da biopolítica. O desenvolvimento da política do bíos, com as técnicas para cuidar da vida, também têm suas contradições. Principalmente com a introdução da zoé que, para Agamben (2007, p. 12), corresponde à vida nua. A redução da vida ao biológico tem várias consequências ético-sociais, sendo uma delas o apagamento da memória como foi feito pelo nazismo, um dos mais inquietantes exemplos.

As técnicas de policiamento são consideradas por Agamben (2007, p. 13) como um aspecto desse reducionismo da vida ao nível da zoé. Assim, o policiamento assumiu um papel importante na definição dos inimigos internos e externos do Estado, bem como foi usado para fornecer verniz de cientificidade para as práticas eugênicas que prescrevem o ideal de pureza racial (AGAMBEN, 2007, p. 154). Foucault (2005, p. 332-333) compreende que a polícia é parte das técnicas de policiamento, que se insere no âmbito da disciplina aperfeiçoada pelo biopoder e utilizada pela medicina desde o século XVIII, assim como por outras ciências no século XIX, na aplicação da teoria da degenerescência racial e nos aparelhos dos Estados totalitários do século XX como o fascismo, nazismo e o stalinismo. No campo biopolítico, Foucault (1994, p. 150) analisou sobre a doutrina da polícia, que tem como objeto o homem e, ao mesmo tempo, “[...] define a natureza dos objetos da atividade racional do Estado, define a natureza dos objetivos que ele persegue, a forma geral dos instrumentos que ele emprega"4.

Para Agamben (2007, p. 14), a biopolítica é tão antiga quanto a exceção, uma vez que já estava presente no poder soberano que, na passagem do súdito ao cidadão, investiu-se na vida nua do homem, tornando-o sujeito político (corpo biopolítico) conforme o princípio de soberania. Neste sentido, o que significa o viver bem segundo a biopolítica? Transformar a

4 Tradução “[...] définit la nature des objets de l'activité rationnelle de l'État; elle définit la nature objectifes qu’il poursuit, la forme générale des instruments qu’il emploie” (FOUCAULT, 1994, p. 150). 
vida nua (zoé) em bios (gerir politicamente a vida nua). Excluir a vida nua do bíos qualificandoa. Deste modo, é no campo da política que o viver se torna um viver bem, da qual se exclui incluindo a zoé politizada, "[...] em que o viver deve se transformar em viver bem, e aquilo que deve ser politizado fosse desde sempre a vida nua. A vida nua tem, na política ocidental, este singular privilégio de ser aquilo sobre cuja exclusão se funda a cidade dos homens." (AGAMBEN, 2007, p. 15).

Se o viver bem depende da medicina para cuidar da saúde do corpo físico, quando passa para o Estado, entra de novo na vida nua (AGAMBEN, 2007, p. 152). No estado de exceção há regra privilegiada de aplicação à vida nua. Não é a exceção a lei, a regra, mas a lei é a exceção (FOUCAULT, 1999a, p. 135). Para Agamben (2007, p. 26), o estado de exceção é permanente, e em determinados momentos a qoé e bíos se tornam a mesma coisa, indistintamente convergindo ao colocar em questão a vida, seja nua ou qualificada,

[...] quando as suas fronteiras se esfumam e se indeterminam, a vida nua que o habitava liberase na cidade e torna-se simultaneamente o sujeito e o objeto do ordenamento político e de seus conflitos, o ponto comum tanto da organização do poder estatal quanto da emancipação dele (AGAMBEN, 2007, p. 17).

Entretanto, frente às contradições do biopoder, Esposito (2010, p. 24-25) encontra em Nietzsche uma visão positiva da biopolítica enquanto que a visão de Foucault é considerada como uma crítica da biopolítica. Para Esposito, o que caracteriza a biopolítica é o caráter imunitário que potencializa a vida encontrada em Nietzsche que corresponde,

Assumir a vontade de poder como o impulso vital fundamental significa afirmar do mesmo passo que a vida tem uma dimensão constitutivamente política e que a política não tem outro escopo que não seja a manutenção e extensão da vida (ESPOSITO, 2010, p. 25).

Assim, Esposito considera que a noção de biopolítica está na centralidade do pensamento de Foucault e que ele se questiona sobre o paradoxo dessa tecnologia, "[...] porque é que até hoje, uma política da vida ameaça sempre transformar-se numa obra de morte?" (ESPOSITO, 2010, p.23). Esposito entende que a entrada da biopolítica na Modernidade é linear e que o tempo a define, enquanto que, para Foucault, o que inaugura a Modernidade é um problema, no caso a relação de zoé e política. O desdobramento decorrente dessa relação coloca em evidência o perigo crescente de uma dialética tanatopolítica da morte (cf. ESPOSITO, 2010, p. 24). Além de em Nietzsche, em Hannah Arendt, Esposito encontra “[...] uma biopolítica afirmativa capaz de virar ao contrário a política de morte nazi e a transformar numa política já não sobre, mas da [grifo do autor] vida" (ESPOSITO, 2010, p. 27).

Esposito critica Foucault e concorda com Agamben de que o poder soberano permanece na Modernidade, quando afirma que “[...] a soberania não está nem antes nem depois da biopolítica, atravessa antes todo o seu horizonte fornecendo a mais potente resposta ordenativa ao problema moderno da autoconservação da vida" (ESPOSITO, 2010, p. 89). Mas, o que caracteriza o paradigma moderno nesta análise? Para Esposito a imunitas, que é o que caracteriza a biopolítica, de modo que se pode dizer que a imunitas define a Modernidade.

O paradigma imunitário sintetiza a relação intrínseca da zoé e bios, vida e política, que liga um ao outro. "A imunidade não é apenas a relação que liga a vida ao poder, mas o poder de conservação da vida" (ESPOSITO, 2010, p. 74). Isso demonstra que as relações de poder

PRACS: Revista Eletrônica de Humanidades do Curso de Ciências Sociais da UNIFAP https://periodicos.unifap.br/index.php/pracs ISSN 1984-4352 Macapá, v. 12, n. 1, p. 65-75, jan./jun. 2019 
não acontecem no exterior à vida, mas por dentro. Neste sentido, Esposito (2010, p. 74) compreende que "[...] a política não é senão a possibilidade, ou o instrumento, de conservar viva a vida". Todavia, imunizar também tem um sentido negativo. Para se proteger, este imunizar pode implicar em eliminar, em matar, em uma proteção negativa da vida que introduz a inoculação no corpo, seja individual ou coletivo (cf. ESPOSITO, 2010, p. 74-75). Deste modo, o paradigma imunitário analisado por Esposito é parte fundamental da biopolítica.

$\mathrm{Na}$ Contemporaneidade, o que caracteriza a imunização é a sua incorporação na política do Estado como uma tanatopolítica, o que se dá principalmente pelos regimes totalitários, ou seja, uma política da morte, tal como o nazismo. O racismo é parte fundamental dessa tanatopolítica que mata quando "[...] a morte dos outros é o fortalecimento biológico da própria pessoa na medida em que ela é membro de uma raça ou de uma população, na medida em que se é elemento numa pluralidade unitária e viva" (FOUCAULT, 2005, p. 308). O nazismo representa o apogeu da biologização da política como nunca antes havia acontecido, exercitando um racismo extremista. "Afinal de contas, o nazismo é, de fato, o desenvolvimento até o paroxismo dos mecanismos de poder novos que haviam sido introduzidos desde o século XVIII" (FOUCAULT, 2005, p. 309).

Diante dessa tanatopolítica, Esposito vai questionar: o que é a biopolítica depois do nazismo? Valendo destacar que a derrota do nazismo não significou o fim da biopolítica. "Não foi a biopolítica que foi um produto do nazismo, mas quando muito foi o nazismo o resultado extremo e perverso de uma particular versão da biopolítica” (ESPOSITO, 2010, p. 209). Esposito demonstra que a biopolítica se reconfigurou em novas questões que surgiram após a Segunda Guerra Mundial e o fim da União Soviética. A imunização ganha novos contornos nos opostos de guerra e paz, ataque (invasão) e defesa, destruição do meio ambiente e preservação ambiental. "A ideia - e a prática - [grifo do autor] da guerra preventiva constitui o ponto mais agudo desta espiral auto-imunitária da biopolítica contemporânea” (ESPOSITO, 2010, p. 211).

\section{CONSIDERAÇÕES FINAIS}

Na temática da biopolítica desenvolvida nessa pesquisa, se percebe que tal tecnologia do poder tem uma preocupação com a vida, entretanto, de modo paradoxal e com seus excessos, fazendo com que a política decida quem deve viver ou morrer (cf. FOUCAULT, 2005, p. 303). Neste sentido, existe uma constante redução da vida a vida nua, a zoé e sua politização. Contudo, Foucault analisa uma nova compreensão da ideia de vida que foi desenvolvida pelas ciências e que diverge da tradição filosófica e da teologia, bem como o sujeito moderno e a sexualidade. No âmbito analítico, para o filósofo, o problema do racismo está na questão do deixar/fazer viver ou deixar morrer. $\mathrm{Na}$ Contemporaneidade, no entanto, o racismo ou a tanatopolítica é que decide quem deve nascer ou quem deve morrer e isso tem se atualizado através das guerras e na destruição do meio ambiente.

Deste modo, percebe-se, que, por um lado, a eugenia se reveste de uma nova roupagem na atualidade, o estado de exceção continua presente através da ação policial e, como apontou Esposito (2010, p. 211), as guerras intermináveis. E que, por outro lado, a biopolítica busca garantir um viver bem da população no que se refere às políticas que tentam afirmar a vida. Não há somente um lado negativo da biopolítica que controla a vida e mata, mas há também uma visão positiva do cuidado e potencialização que qualifica a vida. 


\section{REFERÊNCIAS}

ABRAHAM, Tomás. La sexualidad en el uso de los praceres. In: ABRAHAM, Tomás (Org.). Foucault y la ética. 4. ed. Buenos Aires: Editorial Biblos, 1992.

ADVERSE, Helton. Foucault e a História da sexualidade: da multiplicidade das forças à biopolítica. Aurora. Curitiba, v. 28, n. 45, p. 927-948, set./dez. 2016.

AGAMBEN, G. Homo sacer: o poder soberano e a vida nua. Tradução de Henrique Burigo. Belo Horizonte: Editora UFMG, 2007.

CANDIOTTO, Cesar. Foucault: uma história crítica da verdade. Trans/Form/Ação. São Paulo, n. 29, v. 2, p. 65-78, 2006.

CANDIOTTO, Cesar. Verdade e diferença no pensamento de Michel Foucault. KRITERION. Belo Horizonte, no 115, p. 203-2017, jun. 2007.

CASTRO, Edgardo. Vocabulário de Foucault. Tradução de Ingrid Muller Xavier. Belo Horizonte: Autêntica, 2009.

CORRÊA, Murilo D. Costa. Da Dobra à Obra: Ética de si, estética da existência, verdade e amizade em Michel Foucault. CAPTURA CRÍPTICA: direito, política, atualidade. Florianópolis: UFSC, n.2, v.1, p. 475-522, jul./dez. 2009.

DREYFUS, H.; ROBINOW, P. Michel Foucault: uma trajetória filosófica (para além do estruturalismo e da hermenêutica). Rio de Janeiro: Forense Universitária, 1995.

ESPOSITO, Roberto. Bios: biopolítica e filosofia. Tradução de M. Freitas da Costa. Lisboa: Edições 70, 2010.

FOUCAULT, Michel. A verdade e as formas jurídicas. 3. ed. Tradução de Roberto C. de M. Machado e Eduardo J. Moraes. Rio de Janeiro: NAU Editora, 2002.

FOUCAULT, Michel. Dits et écrits, IV. Paris: Gallimard, 1994.

FOUCAULT, Michel. Em defesa da sociedade. Tradução Maria Ermantina Galvão. São Paulo: Martins Fontes, 2005.

FOUCAULT, Michel. História da sexualidade 2: o uso dos prazeres. 8. ed. Tradução de Maria T. da C. Albuquerque. Rio de Janeiro: Graal, 1998.

FOUCAULT, Michel. História da sexualidade I: a vontade de saber. 13. ed. Tradução de Maria T. da C. Albuquerque e J. A. Guilhon Albuquerque. Rio de Janeiro: Graal, 1999a.

FOUCAULT, Michel. Nascimento da biopolítica. Tradução Eduardo Brandão. São Paulo: Martins Fontes, 2008a.

FOUCAULT, Michel. O nascimento da medicina social. In: MACHADO, Roberto(Org.). Microfísica do poder. 2. ed. Tradução de Roberto Machado. Rio de Janeiro: Paz e Terra, 2015.

FOUCAULT, Michel. Os anormais. Tradução de Eduardo Brandão. São Paulo: Martins Fontes, 2001.

FOUCAULT, Michel. Segurança, território, população. Tradução de Eduardo Brandão. São Paulo: Martins Fontes, 2008b.

FOUCAULT, Michel. Sexualidade e poder. In: MOTTA, Manoel B. (Org.). Ditos e Escritos, V. Ética, sexualidade, política. Tradução de Elisa Monteiro e Inês A. D. Barbosa. Rio de Janeiro, Forense Universitária, 2004.

FOUCAULT, Michel. Verdade e subjectividade (Howison Lectures). In: Revista de Comunicação e linguagem. Lisboa: Edições Cosmos, n. 19, p. 203-223, 1993.

FOUCAULT, Michel. Vigiar e punir: o nascimento da prisão. 20. ed. Tradução de Ra- 
quel Ramalhete. Petrópolis: Vozes, 1999b.

REVEL, Judith. Dicionário de Foucault. Tradução de Anderson Alexandre da Silva. Rio de Janeiro: Forense Universitária, 2011.

TERNES, J. Foucault, do retorno da linguagem ao dizer-verdadeiro. Aurora. Curitiba, v. 23, n. 32, p. 131-144, jan./jun. 2011.

VEYNE, Paul. Foucault: o pensamento, a pessoa. Tradução de Luís Lima. Lisboa: Edições Texto e Grafia, 2009.

WELLAUSEN, Saly da S. Os dispositivos de poder e o corpo em "Vigiar e punir". Margareth Rago e Adilton Luís Martins (Org.). Revista Aulas. Dossiê Foucault. N. 3, dez. 2006/mar. 2007. 